\title{
DIFFERENTIAL EQUATIONS
}

PART II 


\section{Differential}

Equations

\section{Part II}

L. W. F. ELEN, M.Sc.

Principal Lecturer in Mathematics

West Ham College of Technology

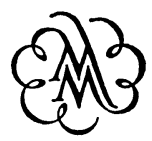

Macmillan Education 
(C) L. W. F. Elen 1967

Softcover reprint of the hardcover 1st edition 1967

ISBN 978-1-349-00051-7

ISBN 978-1-349-00049-4 (eBook)

DOI 10.1007/978-1-349-00049-4

Published by

MACMILLAN \& GO LTD

Little Essex Street London wc2

and also at Bombay Calcutta and Madras

Macmillian South Africa (Publishers) Pty Ltd Fohannesburg

The Macmillan Company of Australia Pty Ltd Melbourne

The Macmillan Company of Canada Ltd Toronto 


\section{Preface}

Modern applications of differential equations require an extensive knowledge of many aspects of mathematical theory. This volume sets out the most frequently used techniques together with the theory of some of the more advanced functions derived from differential equations.

Although not directed towards any particular syllabus this volume, together with Volume I, adequately covers the differential equation requirements of most science and engineering courses at degree level.

The author again wishes to thank the Senate of the University of London for permission to make use of examination questions.

L. W. F. ELEN 


\section{Contents}

\section{Bessel functions}

Error, gamma and beta functions. Bessel's equation 1 and Bessel functions. Recurrence formulae. Lommel integrals. Relationship between solutions. Applications.

\section{Orthogonal polynomials}

Eigenvalues and eigenfunctions. The properties of

Legendre, Tchebyshev, Hermite and Laguerre polynomials.

3 Complex variables and contour integration Differentiation. Regular functions. Cauchy-Riemann equations. Integration. Cauchy's theorem. Singularities. Residues. Examples of contour integration.

\section{The Laplace transform}

Unit step function. Unit impulse function. The convolution integral. Further transforms. Partial differential equations. The inversion theorem and applications.

\section{Fourier transforms}

Finite sine and cosine transforms. Fourier's integral theorem. Infinite sine, cosine and complex transforms. Applications.

\section{Stability of linear systems}

Stability tests and applications. 
viii CONTENTS

7 Non-linear Equations

Equations integrable in exact terms. Riccati's equa- 175 tion and equations soluble by elliptic functions. The phase plane. Methods of perturbations. Solution by Fourier series.

\section{Numerical solution of differential equations}

Picard's and Taylor's series. Adams-Bashforth 207 formulae. Milne-Simpson method. Solution of ordinary and partial differential equations by relaxation methods. 